Marie-Pierre Dargnies*

\title{
Men too sometimes shy away from competition: The case of team competition
}

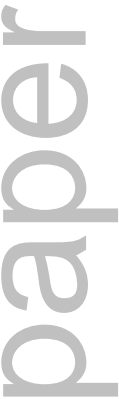

Discussion Paper SP II 2011-201

March 2011

Social Science Research Center Berlin (WZB)

\author{
Research Area: \\ Markets and Politics \\ Research Unit: \\ Market Behavior \\ http://www.wzb.eu/mp/vam \\ E-mail: dargnies@wzb.eu
}

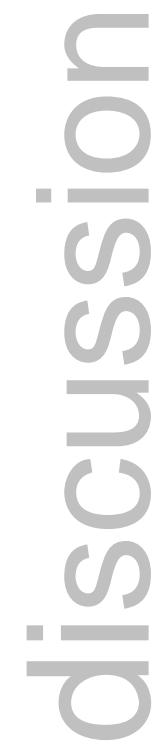

Wissenschaftszentrum Berlin für Sozialforschung (WZB) •

Reichpietschufer 50 • D-10785 Berlin • www.wzb.eu 
(c) The copyright remains with the authors

Marie-Pierre Dargnies

Men too sometimes shy away from competition: The case of team competition

Discussion Paper SP II 2011-201

Wissenschaftszentrum Berlin für Sozialforschung (2011)

* I am grateful to Guillaume Hollard for his enlightening comments and attentive reading and to Maxim Frolov for programming the experiment. I would also like to thank Lise Vesterlund and Muriel Niederle for their encouraging and insightful comments, Jim Andreoni, Matthias Sutter, Jean-Marc Tallon, Jean-Christophe Vergnaud and Marie-Claire Villeval for very helpful remarks and Thomas Baudin for his careful reading. I am also grateful to numerous seminar participants at the ESA conference in Lyon, the Microeconomic Workshop of Paris 1, the Crem seminar in Rennes, the CEE conference in Copenhagen, the IMEBE conference in Granada and the PET conference in Galway. Finally, I want to thank ANR BLANO7-2_192879 for financial support.

Social Science Research Center Berlin (WZB)

Research Area:

Markets and Politics

Research Unit:

Market Behavior
Wissenschaftszentrum Berlin für Sozialforschung gGmbH (WZB)

Forschungsschwerpunkt:

Märkte und Politik

Abteilung:

Verhalten auf Märkten

Reichpietschufer 50, D-10785 Berlin

Telefon: +49 30 25491-0, Fax: +4930 25491-440

http://www.wzb.eu 


\begin{abstract}
Recent results in experimental and personnel economics indicate that women do not like competitive environments as much as men. This article presents an experimental design giving participants the opportunity to enter a tournament as part of a team rather than alone. While a large and significant gender gap in entry in the individual tournament is found in line with the literature, no gender gap is found in entry in the team tournament. Women do not enter the tournament significantly more often when it is team-based but men enter significantly less when they are part of a team rather than alone. The main reason for men's disaffection for the team competition appears to be linked to the uncertainty on their teammate's ability. More precisely, high-performing men fear to be the victims of the free-riding behaviour of their teammate.

Keywords: Teams, Gender Gap, Tournament
\end{abstract}




\section{Introduction}

The existence of a gender gap in income and social positions in the American and European labor markets is a well known fact. ${ }^{1}$ The wage gap increases for highly educated workers as one moves up the distribution, as shown by De la Rica et al. (2008). Using a sample composed of a large group of US firms, Bertrand and Hallock (2001) found that only $2.5 \%$ of the executives in their sample were women. Such a well documented fact has received various explanations ${ }^{2}$

This article belongs to a literature interested in one particular explanation for the gender gap: a difference between genders in the taste for performing in competitive environments. For instance, Fox and Lawless (2004) showed that women who share the same personal characteristics and professional qualifications as men express significantly lower levels of political ambition to hold elective office.

Experimental economics has proven to be a useful tool for studying gender differences in the propensity to enter competitive environments, as it enables one to study the competitive behaviour of participants in a real-effort exercise while carefully controlling for potential explanations. The core idea is to compare subjects' choices between a remuneration scheme which does not imply competition, i.e. a piece rate, and one that does, i.e. a tournament. Variations in the protocol are used to disentangle the respective explanatory power of alternative explanations. Participants thus have to make successive choices in slightly different environments. An important contribution along this line is Niederle and Vesterlund (2007). Their main result is that women choose to enter the tournament far less often than men, resulting in a male-dominated pool of entrants. ${ }^{3}$ More precisely, low-performing men enter the tournament too often while high-performing women do not enter enough, when taking payoff-maximizing choices into consideration. These results show that a substantial gap remains after adding controls for all expected effects such as overconfidence and risk and ambiguity aversion. This residual gap is attributed to a difference between genders in the taste for performing under the pressure of competition. It is worth wondering whether men are more competitive than women per se or if it depends on the modalities of competition in which case one could try to think of changes in institutions that may lead to an equal representation of both genders among competitors.

This article explores team competition as a way of reducing the gender gap in tournament entry and getting the best performers to self-select into the competition. Indeed, when they have the option, people

\footnotetext{
${ }^{1}$ See Anker (1998) among the numerous references on the subject

${ }^{2}$ See for example Goldin and Rouse (2000), Altonji and Blank (1999)

${ }^{3}$ See "Do Women Shy Away From Competition? Do Men Compete Too Much?" (Niederle and Vesterlund, 2007), "Male and Female Competitive behaviour: Experimental Evidence" (Gupta et al., 2005) and "How Costly is Diversity? Affirmative Action in Light of Gender Differences in Competitiveness" (Niederle et al., 2008)
} 
often choose to engage in competition with a teammate rather than alone. One can think for instance of academic publication where papers are often co-authored or of invitations to tender which frequently oppose several teams, each representing a firm. Numerous experimental results suggest that the decision-making process may be more efficient among teams than for individuals: teams are faster learners than individuals (Cooper and Kagel, 2005, Kocher and Sutter, 2005), they take more risks when it enables them to get higher expected earnings (Rockenbach et al., 2007) and they play closer to the predictions of game theory (Luhan et al., 2009, Bornstein and Yaniv, 1998). However, as other experimental results point towards less efficiency of groups in comparison with individuals (Cason and Mui, 1997, Cox and Hayne, 2006), it is not straightforward to predict how the team membership will affect subjects' willingness to compete. One of the main question is whether the team tournament will do a better job of attracting the best candidates into the competition than the individual tournament. In the present experiment, participants actually make the decision whether to enter the team competition on their own. While one can think that the competitive decision may be very different when team members decide together whether to enter the competition, it allows to avoid the confound that men and women may be different in their propensity to be talked into entering a competition.

There are several channels through which the competition being team-based rather than individual may affect differently men and women's competitive behaviour. Men and women's confidence in their chances of winning the tournament as well as their risk and ambiguity aversion might be affected in a different way. Men and women may also react differently to the fact that, when belonging to a team, one's payoffs are influenced by one's teammate's performance and one's performance influences one's teammate's payoffs. Healy and Pate (2010) have also conducted an experiment in order to study the effect of a competition being team-based on gender differences in willingness to compete. However, their experimental design does not allow to fully understand the changes in competitiveness when the tournament goes from being individual to being team-based. In particular, their experimental design does not control for the role of the uncertainty on one's teammate's performance which turns out to be very important in the present experiment.

Finally, men and women may experience modifications in their taste for competition (for instance, women may come to like competition more as part of a team or men may not enjoy it as much).

The notion of team used in the present article is the most simple one so as not add more complexity: a team is composed of two teammates who perform separately without knowing the identity of their teammate. Being part of a team to compete may have an effect on one's willingness to enter the competition. 
This intuition is supported by a growing literature in experimental economics which shows that group membership greatly affects individual behaviors. Chen and Li (2009) show that their participants behave more altruistically with an ingroup match than with an outgroup. Charness et al. (2007) show that when group membership is made salient, either by common payoffs or by letting an audience of group members watch the decision-maker, decisions tend to favor more the payoffs of the whole group and Sutter (2009) finds that, in an investment experiment, the decisions made individually by one group member are very similar to the decisions taken jointly by all the members of a team.

The present experiment may add to the findings on group membership, as participants have to decide whether or not to become a member of a team in order to enter a tournament. Comparing the effort of participants who could choose whether to be part of a team to that of participants who were forced to belong to a team, Keser and Montmarquette (2007) found that voluntary teaming significantly increases the level of effort. Having the option to be part of a team may also well have an effect on subjects' competitiveness.

The first result of this article is that no gender gap in entry is observed when the tournament is teambased, while the individual tournament produces a significant gender gap in line with Niederle and Vesterlund (2007) and Niederle et al. (2008), henceforth NV and NSV. Whereas women enter as often alone as when part of a team, men and, more precisely, high-performing men, enter significantly less often when part of a team. In a field experiment, List and coauthors (2010) also find that men are reluctant to enter team-based competitions.

In the present experiment, almost all men with an above median performance chose to enter the individual tournament but many of them opted out of the standard team tournament. To allow us to find out more clearly what caused the change in competitive behaviour when the competition was team-based rather than individual, participants had one more choice to make. They had to choose between a piece rate and a specific kind of team tournament, for which the information that they will be matched with a teammate of a level close to their own is added. This last choice was not included in Healy and Pate (2010) and allows one to understand the reasons behind men's lack of interest in the team competition. Indeed, when they knew they would be matched to an equally able teammate if they entered the team tournament, most high-performing men were back in the tournament.

High-performing men's reluctance to enter the team tournament may therefore either come from their unwillingness to help a possibly less able teammate get higher payoff or from their fear of being subjected to their teammate's free-riding behaviour. In order to disentangle these two potential explanations, the 
role of beliefs in the decision to enter is analysed and the task 4 prime and 5 prime decisions to submit a past performance to respectively the team tournament and the team tournament with a teammate of the same level are used. The decision to submit a past performance to the team tournament is identical to the decision to enter the same tournament as far as overconfidence, risk aversion and the uncertainty about one's teammate's ability are concerned. It only differs in that it does not involve a future performance from either teammate. In particular, when deciding whether to submit a past performance to the team tournament, one knows her teammate has performed the task already under an individual remuneration scheme (piece rate). High-performing men are about as likely to submit their past performance to the team tournament and the team tournament with a teammate of the same level. This indicates that the reason why high-performing men are reluctant to enter the team tournament with a teammate of unknown ability is that they do not want to be subjected to the free-riding behaviour of their teammate.

Team tournaments help get a gender-balanced pool of entrants, offering women equal chances of winning the competition. Nevertheless, the tournament being team-based negatively affects the quality of the pool of candidates as many high-performing men do not enter the team tournament. Team competition thus does not allow to get the best performers to self-select into the competition. A way of achieving both an equal representation of genders among entrants and a good quality of the pool of competitors is to assure participants that they will be matched with someone of about the same ability as their own if they choose to enter the team tournament.

The rest of the article is organized as follows. Section 2 presents the experimental design. The results are given in Section 3. Section 4 studies the consequences on welfare of the type of tournament. Finally, Section 5 provides some concluding remarks.

\section{Experimental Design}

The experimental design builds on that of NV. The basic idea is to have participants choose a remuneration scheme between a piece rate and a tournament before they have to perform the exercise determining their payoffs. The exercise subjects were asked to perform is the same as in NV: additions of five 2-digit numbers. Participants were told that they had to complete eight tasks sequentially ${ }^{4}$ of which two would be randomly chosen for payment at the end of the experiment. The remuneration schemes available (in particular the

\footnotetext{
${ }^{4}$ The fact that tasks are completed sequentially may obviously have an effect on subjects decisions to compete as learning could occur and affect these decisions. However, as this paper focuses on gender effects, the relevant question should be whether men and women are affected in a different way by the tasks being sequential and it is, in my opinion, unlikely.
} 
tournament being rather individual or team-based) changed between tasks and the switches in the choice to enter the tournament provided information on the reasons behind the competitive behaviors.

Teams are tricky to handle and one had to be as careful as possible not to introduce more complexity than needed in the matching process. Teams are composed of two teammates who will not know whether they are matched with a man or a woman as this may well have an impact on one's decision to enter the team tournament. Therefore, subjects have to choose whether to be paid according to a piece rate or a team tournament in which case they will win their tournament if their teammate and themselves solve more additions than their two randomly chosen opponents.

One major change of the competition being team-based rather than individual is that, in a team tournament, a subject influences her teammate's payoffs and have her teammate influence her own payoffs. In order to control for this factor on one's decision to enter the team tournament, participants also had to make a choice between a piece rate and a team tournament with a teammate of the same level. In this specific kind of team tournament, a participant knew that if she chose to enter she would be matched with a participant with a past performance close to her own. The switches in competitive behaviour arising when the matching process changes provide information about the importance of knowing the level of one's teammate when choosing whether to compete.

This section first presents the different effects which needed to be controlled for before detailing the tasks participants had to go through.

\subsection{What Needs to be Controlled for}

The experimental design needs to allow one to disentangle the role played by several factors in explaining the change in the gender gap in entry when the tournament becomes team-based. In order to avoid making the design even more complicated than it already needs to be, the notion of team I selected is the most simple one: two teammates who would not be aware of the identity of their teammate or of that of their opponents. This way, the effect of the gender of one's teammate or opponents on the decision to enter the tournament does not have to be taken into account. Every potential effect of the team tournament had then to be listed before an appropriate way to control for it was found.

First of all, the tournament being team-based rather than individual changes one's expected payoff from entering the tournament for each level of performance. Nevertheless, as the probability changes in the exact same way for men or women, conditional on performance, it is unlikely that this change of probability might 
cause a reduction in the gender gap in tournament entry.

Secondly, NV and NSV found a significant gender gap in overconfidence. It could be the case that overconfidence about one's team chances of winning the tournament differs from overconfidence about one's chances to win the individual tournament. Tajfel (1970) discovered that groups formed on the basis of almost any distinction are prone to ingroup bias. Within minutes of being divided into groups, people tend to see their own group as superior to other groups. It could be the case that men and women differ in how they are affected by this ingroup bias. Women could for example be more optimistic than men about their teammate's performance.

Thirdly, being part of a team could have a different effect on men's and women's ambiguity, risk or feedback aversion. Teams and individuals do not have the same risk preferences. Shupp and Williams (2007) found that the variance of risk preferences is generally smaller for groups than individuals and the average group is more risk averse than the average individual in high-risk situations, but groups tend to be less risk averse in low-risk situations. Rockenbach et al. (2007) showed that compared to individuals, teams accumulate significantly more expected value at a significantly lower total risk. In spite of the fact that this paper is interested in the preferences of individuals, being part of a team may have a different impact on men's and women's individual risk preferences. Women could, for example, be less risk averse as part of a team than alone.

Fourthly, in a team competition one's performance influences one's teammate's payoffs and one's payoffs are influenced by one's teammate's performance. For instance, if my teammate is worse than I am, it will lower both my probability of winning the tournament and my payoff if we do win. Charness and Jackson (2009) explore play between groups where one member of each 2-person group dictates the play of that group and is therefore responsible for the payoff of the other group member. They find that a substantial part of the population plays a less risky strategy when choosing for a group than when playing only for themselves. Again, men and women may react differently to this responsibility issue.

Men and women may also not respond in the same way to the possible free-riding behaviors of their teammate.

Lastly, the taste for competing might change depending on whether one is part of a team or alone. Niederle and Vesterlund (2007) found that, after controlling for differences in overconfidence, risk, ambiguity and feedback aversion, the gender gap in tournament entry was not entirely accounted for. They label the residual explanation as a gender difference in the taste for performing in a competitive environment. The fact that 
the tournament is no longer an individual one could have a different impact on men's and women's thrill or fear of competition. Indeed, a literature interested in gender differences in economic decisions (Eckel and Grossman, 1998, 2001, 2008, Ortmann and Tichy, 1999) finds that women tend to be more socially-oriented and less individually-oriented than men as well as more cooperative and less selfish. If team competition succeeds in wiping out the gender gap in the taste for competition, it could show that institutionnal changes can be successful in making men and women equally willing to compete. The following subsection presents the tasks the participants had to go through and explains how they allow one to control for the effects listed in the present subsection.

\subsection{The Tasks}

The experimental sessions were run in September 2008. ${ }^{5} 39$ men and 37 women took part in one of the 6 experimental sessions. The average participant earned 15,86 euros including a 7-euro show-up fee.

At the end of each task, participants were informed of their absolute performance (the number of additions they correctly solved) but were not informed of their relative performance until the end of the experiment. Participants received instructions on a task only immediately before completing it.

Task 1. piece rate: Participants are given the three-minute addition exercise. If Task 1 is randomly chosen for payment, they receive 50 cents per correct answer.

Task 2. individual tournament: Participants are given the three-minute addition exercise. If Task 2 is chosen for payment, the subject receives 1 euro per correct answer if she solved more additions than her randomly chosen opponent, otherwise she receives nothing.

Task 3. Choice between piece rate (PR henceforth) and individual tournament (IT henceforth): Before they perform their additions, subjects have to choose whether they want to be paid according to the piece rate (50 cents per correct answer) or the individual tournament compensation scheme. A participant who selects the tournament receives 1 euro per correct answer if her Task 3 performance exceeds the Task 2 performance of a randomly chosen opponent, otherwise she receives nothing. In the present article, a participant in the individual tournament is the winner if she beats one opponent. In NV, one had to beat the performances of three other participants to be considered the winner of the tournament. Here, I chose to consider a one-toone competition as a matter of simplicity since I subsequently needed to introduce teams. This one-to-one

\footnotetext{
${ }^{5}$ Subjects were recruited through the online recruitment system ORSEE (Greiner, 2004). The experiment was computerized using the REGATE software (Zeiliger, 2000).
} 
competition could have an effect on the participants' decision to enter. Subjects are furthermore competing against a competitive performance of their opponent so that the decision to enter the tournament is not affected by beliefs about whether the opponent is going to enter. In addition, it allows one to rule out the possibility that a participant may not enter because she may fear to inflict losses on her opponent.

Task 3 prime. Choice between submitting Task 1 performance to piece rate or individual tournament: No additions to do here, the performance which will determine the payoff is the task 1 performance. If a participant chooses to submit her task 1 performance to the piece rate, she receives 50 cents times her Task 1 performance. If she chooses to submit her Task 1 performance to the individual tournament, she receives 1 euro per addition correctly solved in Task 1 if she solved more additions than her randomly chosen opponent, otherwise she receives nothing. Task 3 prime is identical to Task 3 (in both cases the tournament is a more risky choice implying more ambiguity and subjecting the participant to feedback at the end of the experiment concerning whether she beat her opponent) except for the fact that it does not involve a future performance. In particular, the participant who chooses to submit her past performance to the tournament does not have to perform under the pressure of competition. In consequence, any change in behavior between Tasks 3 and 3 prime will be attributed to the taste for performing in a competitive environment.

Task 4. Choice between piece rate and team tournament: Subjects have to choose whether they want to be paid according to the piece rate or the team tournament. The team tournament is a two to two competition. If a participant chooses the team tournament, two opponents are randomly drawn among the other participants present in the room. One teammate is randomly drawn among the participants who chose the team tournament. ${ }^{6}$ This implies that a subject who chooses to enter the team tournament knows that her teammate will have made the same choice so that both teammates will be competing at the same time against their opponents, facilitating the emergence of a team spirit. If the number of additions solved by one's team during Task 4 exceeds the number of additions solved by the opposing team during Task 2, each teammate receives 1 euro times the average score of their team. Otherwise, they receive nothing. This choice of remuneration for the team tournament was made in order to keep incentives as stable as possible across tournaments.

Task 4 prime. Choice between submitting Task 1 performance to piece rate or team tournament:

\footnotetext{
${ }^{6}$ In the case where only one participant would have chosen the team tournament, which never happened, the teammate would have been drawn among participants who chose the piece rate. Also, if an uneven number of participants chose the team tournament, participants were paired and a teammate was randomly chosen among them whose performance was added to the remaining participant's performance to compute the score of her team.
} 
No additions to do here, the performance which will determine the payoff is the Task1 performance. If a participant chooses to submit her Task 1 performance to the piece rate, she receives 50 cents times her Task 1 performance. If she chooses to submit her Task 1 performance to the team tournament, two opponents are randomly drawn among the other participants present in the room. One teammate is randomly drawn among the participants who chose to submit to the team tournament. ${ }^{6}$ If the number of additions solved by one's team during Task 1 exceeds the number of additions solved by the opposing team during Task 1 , each teammate receives 1 euro times the average score of their team. Otherwise, they receive nothing. Task 4 prime is identical to Task 4 (considering overconfidence, risk aversion and uncertainty about teammate's ability) except for the fact that it does not involve a future performance from either teammate. In particular, the participant knows that her teammate has performed the task already under an individual remuneration scheme (piece rate) and must therefore not fear that her teammate will free-ride on her performance.

Task 5. Choice between piece rate and team tournament with a teammate of the same level (TTid henceforth): If a participant chooses the team tournament with a teammate of the same level, two opponents are randomly drawn among the other participants present in the room. One teammate is attributed from among the participants who chose the team tournament: the participant whose Task 2 performance was the closest to the participant's own Task 2 performance. If the number of additions solved by one's team during Task 4 exceeds the number of additions solved by the opposing team during Task 2, each teammate receives 1 euro times the average Task 5 score of their team. Task 5 resembles Task 4 in that the subjects have to choose between a piece rate remuneration and a team tournament but in Task 5 the uncertainty about one's teammate's ability at solving additions (or at least part of it) is taken away. Then, assuming that learning effects are the same for men and women, if men's and women's behavior changes in a different way between Task 4 and Task 5, it will be attributed to a different reaction to the uncertainty about one's teammate's ability.

Task 5 prime. Choice between submitting Task 1 performance to piece rate or team tournament with a teammate of the same level: No additions to do here, the performance which will determine the payoff is the Task 1 performance. If a participant chooses to submit her Task 1 performance to the piece rate, she receives 50 cents times her Task 1 performance. If she chooses to submit her Task 1 performance to the TTid, two opponents are randomly drawn from among the other participants present in the room. One teammate is attributed from among the participants who chose the team tournament: the participant whose Task 2 performance was the closest to the participant's own Task 2 performance. If the number of additions 
solved by one's team during Task 1 exceeds the number of additions solved by the opposing team during Task1, each teammate receives 1 euro times the average score of their team. Otherwise, they receive nothing.

Since these tasks are completed in the same order by all participants, order effects can play a role, but this paper compares men and women's behavior and it seems reasonable to assume these order effects would be the same for men and women. Indeed, as it turns out, men and women exhibit very different behavioral patterns allowing one to rule out the possibility that order effects drive the results.

\section{Belief-assessment Questions}

A difference in confidence between men and women may explain a significant part of the gender gap in tournament entry. NV and NSV found that both men and women are overconfident but men are more so. In order to control for differences in confidence both in one's chances of winning the individual tournament and in one's team chances of winning the team tournament, participants had to answer belief-assessment questions at the end of the experiment. Participants had to guess the mean Task 1 and Task 2 performances of the participants in their session.

The participants were recalled that during Task 4 they had to choose between a piece rate and a team tournament, for which two opponents were randomly drawn from among the other participants and a teammate was randomly drawn from among the other participants who had chosen the team tournament. They were also told that the computer had picked two opponents and one teammate in this way regardless of their Task 4 choice (i.e. even if they had chosen the piece rate at Task 4). Their own Task 2 performance was recalled to them and participants had to guess the Task 2 performances of their teammate and opponents chosen during Task 4.

The participants were recalled that during Task 4 prime they had to choose between submitting their Task 1 performance to either a piece rate or a team-tournament, for which two opponents were randomly drawn from among the other participants and a teammate was randomly drawn from among the other participants who had chosen to submit to the team tournament. They were also told that the computer had picked two opponents and one teammate in this way regardless of their Task 4 prime choice (i.e. even if they had chosen the piece rate at Task 4 prime). Their own Task 1 performance was recalled to them and participants had to guess the Task 1 performances of their teammate and opponents of Task 4 prime. A participant knew she would earn 1 euro per correct guess. 


\section{Results}

This section presents the results of this experiment. In the first subsection, the disappearance of the gender gap which occurs when the tournament comes from being individual to being team-based is studied. It is furthermore shown that it is mainly due to men who are a lot less likely to enter the tournament when it is team-based. In a second subsection, the reasons behind men's change in competitive behavior are investigated.

\subsection{Gender Gap in Entry in the Individual and Team Tournaments}

In this subsection, the gender gaps in both the individual and the team tournaments are studied.

\subsubsection{Gender Differences in Entry in the Individual Tournament}

In line with NV, there is a gender gap in the decision to enter the individual tournament: $51.35 \%$ of women and $84.62 \%$ of men chose to enter the individual tournament. This difference is significant with a two-sided exact Fisher's test $(p=0.00)$.

After having gone through the piece rate and tournament remuneration schemes, participants have to choose which one they want to perform under for Task 3 . If they choose the tournament, they will be considered the winner if they beat the Task 2 performance of their opponent. Considering the true distribution of Task 2 performances, a payoff-maximizing participant should choose the tournament if her task 3 performance is at least 6 (see Figure 10 in the Appendix: an omniscient participant with a performance above or equal to 6 has higher expected payoffs from the individual tournament than from the piece rate). If the participant's Task 3 performance is exactly the same as her Task 2 performance, $62 \%$ of women and $67 \%$ of men have higher expected earnings from the tournament. This predicted gender gap is not significant (a two-sided Fisher's exact test yields $p=0.81$ ).

While significantly more men enter than the proportion whose entry would maximize their expected payoffs given the distribution of performances $(p=0.00)$, it is not the case for women $(p=0.65)$.

This gender gap in competitiveness cannot be explained by a performance gap. Indeed, men's performances were slightly above women's but not significantly so. In Task 1 (piece rate), men solved 5.9 additions on average while women solved 5.6 additions. In Task 2 (tournament), men solved 7.4 additions on average while women solved 6.3 additions. These differences are not significant with a two-sided Mann-Whitney 
test. While men perform significantly better under the tournament than under the piece rate (a two-sided Mann-Whitney test yields $\mathrm{p}=0.04)$, it is not the case for women $(\mathrm{p}=0.34)$.

This gender-gap in tournament entry has several potential explanations: differences in overconfidence between men and women, differences in risk, ambiguity and feedback aversion, differences in the taste for performing in a competitive environment. Firstly, men are found to be more overconfident than women, as found in NV and NSV. At the end of the experiment, participants' Task 2 performance was recalled to them and they had to guess the Task 2 performance of their Task 4 teammate and opponents. From their answer, their guessed rank was computed and the guessed ranks conditional on the actual Task 2 performance (4 levels were assigned, each corresponding to $25 \%$ of participants) were compared.

An ordered logit regression of the guessed rank yields a negative and significant $(p<0.01)$ coefficient of Task 2 performance and a positive and significant effect of Female $(p=0.07)$. This means that the higher the Task 2 performance, the better the participant thinks she is, while, for a given performance, men are more overconfident than women.

In order to also control for the role of risk, ambiguity and feedback aversion in the gender gap in tournament entry, the Task 3 prime decision to submit the Task 1 performance to either a piece rate or an individual tournament is used. Indeed, the Tasks 3 and 3 prime decisions are the same except for the fact that only in Task 3 does the participant actually have to perform in a competitive environment. The Task 3 prime decision therefore allows one to control one more time for one's confidence in her chances to win and adds a new control for risk, ambiguity and feedback aversion. When comparing men and women's Task 3 prime decision, men are found to submit their past performance to the tournament more often than women (54\% vs $43 \%$ ) but the difference is not significant $(p=0.36)$. Since there is indeed a gender gap in the decision to submit a past performance to the tournament, it seems that men may be somewhat less averse to risk, ambiguity and feedback than women. However, since the gender gap in the decision to submit to the individual tournament is much smaller than the gender gap in the decision to enter the tournament, it must mean that most of the gender gap is due to men having a greater taste for performing in a competitive environment. This results are in line with NV and NSV.

\subsubsection{Gender Differences in Entry in the Team Tournament}

Like with the individual tournament, anyone with higher expected earnings from the team tournament than the piece rate should enter the team tournament. As can be seen in Figure 10 of Appendix B, this corresponds 
to participants with a Task 2 performance above or equal to 6 . This is the case of $62 \%$ of women and $67 \%$ of men. The predicted gender gap is not significant $(p=0.81)$.

In line with the predictions, the data do not bring any gender gap to light: $62 \%$ of women and 59\% of men chose to enter the team tournament $(p=0.82)$. Men enter less than what is predicted by payoff maximizing choices but not significantly so $(p=0.49)$. As can be seen in Figure 1, it appears that while women do not choose to enter the tournament significantly more often when it is team-based $(p=0.48)$, men enter significantly less as part of a team than alone $(p=0.02)$.

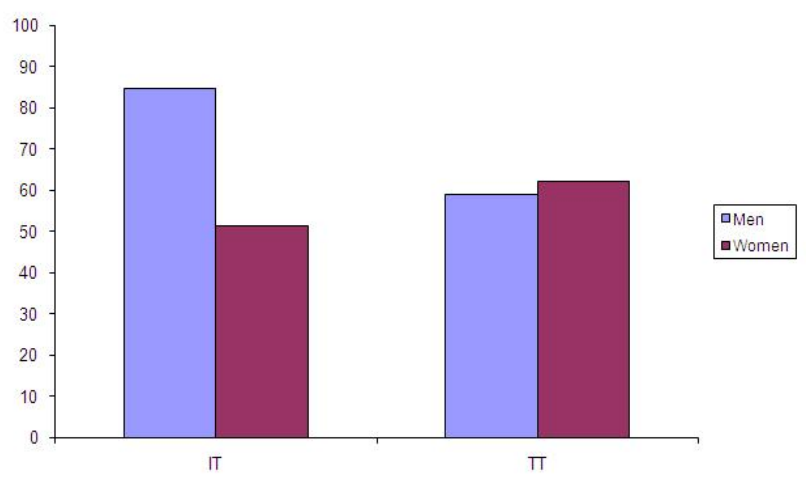

Figure 1. Proportion of male and female entrants in the individual tournament (IT) and team tournament (TT).

A logit regression of the decision to enter a tournament (Tasks 3 and 4) on the probability of winning (Prob) and a team dummy (team $=1$ for the Task 4 decision to enter the team tournament and team $=0$ for the Task 3 decision to enter the individual tournament) is reported in Table 1.

Even though the probability of winning is unknown to the participant, including it to the regressors allows one to compare the efficiency of the different tournaments (Does a given tournament leads the better participants to self-select into it?). As two observations were used for each participant (Task 3 and Task 4 decisions to enter each of the tournaments), a cluster on the participant was used to take into account the fact that the two decisions to enter the tournaments taken by the same individual are not independent. Clusters were also used at the session level in order to take care of the fact that the proportion of men and women varied across sessions.

Conditional on the probability of winning, the fact that the tournament is team-based decreases men's propensity to enter while it has no significant effect on women's decision to enter. The probability of winning has no significant effect on either men's or women's propensity to enter. Overall, participants tend to choose 
Table 1: Linear Probability Model of Tournament-Entry Decision (Tasks 3 and 4)

\begin{tabular}{lccc}
\hline Regressors & Men & Women & All \\
\hline \hline Female & & & -0.25 \\
& & & $(0.00)$ \\
Female*Team & & & 0.19 \\
& & & $(0.01)$ \\
Team & -0.26 & 0.10 & -0.18 \\
& $(0.01)$ & $(0.32)$ & $(0.01)$ \\
Prob & 0.21 & 0.13 & 0.19 \\
& $(0.48)$ & $(0.67)$ & $(0.42)$ \\
\hline Observations & 78 & 74 & 152 \\
\hline \hline
\end{tabular}

Linear-probability model using clusters for each participant and each session.

The table presents marginal effects computed at a man in the individual tournament with a $50 \%$ chance of winning the tournament. P-values are in brackets.

less often to enter the tournament when it is team-based. The positive and strongly significant marginal effect of Female*Team shows that when the tournament is team-based the gender gap in tournament entry is significantly reduced.

Figures 2 and 3 show the percentage of men and women who choose to enter the individual and team tournaments conditional on their Task 2 performance level. The relation between the performance level and the team tournament entry decision is decreasing for men showing that men's disinterest for the team competition is all the more important than they are of a high performance level. The logit regression of men's decision to enter the team tournament on the probability of winning (see the Appendix for an explanation of how the probability of winning was computed) provides a negative but only marginally significant coefficient $(p=0.10)$.

Both low-performing and high-performing women ${ }^{7}$ are a bit more likely to enter the team tournament than the individual tournament but the difference is not significant for both subgroups of women $(p=0.55$ and $p=0.49$ respectively for low-performing and high-performing women). High-performing men on the other hand are much less likely to enter the team tournament than the individual tournament $(p=0.00)$ while this is not the case for low-performing men $(p=0.74)$.

To sum up this subsection, there is a large and significant gender gap in the decision to enter the individual tournament but it is no longer the case when the tournament is team-based. This result is not driven by

\footnotetext{
${ }^{7}$ Low-performing participants are those whose Task 2 performance is below or equal to 6 which is the median Task 2 performance. There is 20 low-performing women and 20 low-performing men. High-performing participants are those whose Task 2 performance is above 6 . This is the case of 17 women and 19 men.
} 


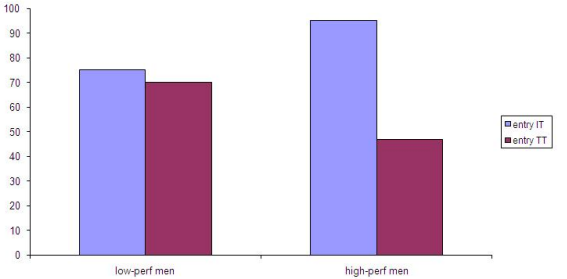

Figure 2. Proportion of men entering the individual and team tournaments conditional on performance level.

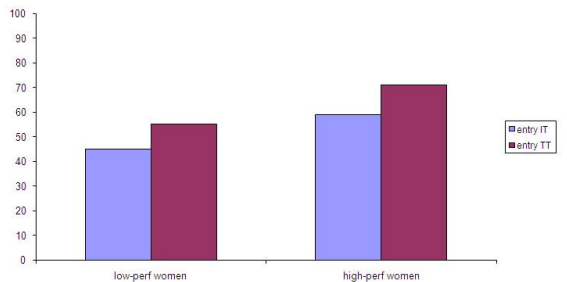

Figure 3. Proportion of women entering the individual and team tournaments conditional on performance level.

women whose competitive behavior is not significantly affected by the nature of the competition. Men, on the other hand, and more precisely high-performing men, are much less likely to enter the competition when it is team-based. The next subsection aims at understanding further men's change of competitive behavior.

\subsection{Why do men shy away from the team competition?}

This subsection aims at understanding the reasons behind men's change of competitive behavior when the competition goes from being individual to being team-based. In the previous subsection, it was shown that the disappearance of the gender gap occuring when the competition is team-based is due to men, and more precisely high-performing men, who shy away from the team competition while they massively entered the individual competition. Several explanations could account for this behavior. Firsly, it could be that part of the reason why men enjoy evolving in a competitive environment comes from their hope of being the sole winner. If this is the case, the perspective of sharing the joy of winning with a teammate will diminish the fun of the competition. Secondly, men may not want to help a possibly less deserving teammate get higher payoffs. Finally, men may fear the freeriding behavior of their teammate.

\subsubsection{Do men enjoy competition less when they are part of a team?}

In order to answer this question, the Task 5 decision to enter the team tournament with a teammate of the same level (TTid) is used in addition to the Task 3 and 4 decisions. The Task 5 decision resembles the Task 4 decision (team tournament) except for the fact that the uncertainty about the level of one's teammate in the addition task (or at least part of it) is removed, since the participant knows that if she enters the tournament she will be matched with a teammate whose Task 2 performance is close to her own. Therefore, if the reason why men do not like the team competition as much as the individual one is that they do not want to share the victory with somebody else, they should also be reluctant to enter the team tournament with a teammate of the same level. 
Figure 4 shows the proportion of low-performing and high-performing men who chose to enter in each of the three tournaments. While low-performing men enter in the three tournaments in very similar proportions, it is not the case of their high-performing counterparts. Indeed, most high-performing men self-select in the individual tournament $(95 \%)$ and the team tournament with a teammate of the same level $(84 \%)$ and the proportion only drops for the team tournament (47\%). Furthermore, the proportions of high-performing men choosing to enter the individual tournament and the team tournament with a teammate of the same level are not significantly different $(p=0.32)$ while high-performing enter significantly more often both the individual tournament and the team tournament with a teammate of the same level than the team tournament ( $p=0.00$ and 0.02 respectively). This indicates that men's disaffection for the team tournament is not due to their not wanting to share the victory with a teammate but rather has to do with the uncertainty surrounding their teammate's ability.

The regressions presented in table 2 confirm that men's disaffection for the team competition comes from high-performing men who are only willing to enter the team tournament if they know their teammate will also be of high performance level. Indeed, when the dummy IdPartn (which equals 1 when the tournament proposed is a team tournament with a teammate of the same level (Task 5) and 0 otherwise) is added to the regressors, the coefficient of Team somewhat increases and it becomes positive and loses all significance when the interaction term for the probability of winning the tournament and Team is in turn added.

Therefore, the reason for men's unwillingness to enter a competition with a teammate could either be that men do not want to help a possibly less deserving teammate get higher payoffs (or, at least that they do not want to risk losing the tournament in order to do so) or that they fear the freeriding behavior of their teammate. The following subsection will help us disentangle these two alternative explanations.

\subsubsection{Are high-performing men unwilling to help a less able participant get higher payoffs?}

According to the previous results, high-performing men's reluctance to enter the team tournament may either come from their unwillingness to help a possibly less able teammate get higher payoff or from their fear of being subjected to their teammate's free-riding behavior. In order to disentangle these two potential explanations, the role of beliefs in the decision to enter will be analysed and the task 4 prime and 5 prime decisions to submit a past performance to respectively the team tournament and the team tournament with a teammate of the same level are used. 
Table 2: Linear Probability Model for Men's Tournament-Entry Decision (Tasks 3, 4 and 5)

\begin{tabular}{lccc}
\hline Regressors & $(1)$ & $(2)$ & $(3)$ \\
\hline \hline Team & -0.26 & -0.19 & 0.05 \\
& $(0.01)$ & $(0.01)$ & $(0.90)$ \\
Prob & 0.16 & 0.26 & 0.92 \\
& $(0.48)$ & $(0.18)$ & $(0.02)$ \\
IdPartn & & 0.11 & 0.11 \\
& & $(0.06)$ & $(0.07)$ \\
Prob*Team & & & -0.84 \\
& & & $(0.07)$ \\
\hline Observations & 78 & 117 & 117 \\
\hline \hline
\end{tabular}

Linear probability model using clusters for each participant and each session.

The table presents marginal effects computed at a man in the individual tournament with a $50 \%$ chance of winning the tournament. P-values are in brackets.

One explanation for high-performing men's reluctance to enter the team tournament unless they know their teammate will also be high-performing could be that they are pessimistic about the performance level of the teammate they expect. To assess the potential explanatory power of beliefs on the change of men's competitive behavior, we use the dummy Guesswin which equals 1 if the participant's beliefs are consistent with winning the tournament, and 0 otherwise. Remember that a participant knows her absolute performance at each task. For the individual tournament, Guesswin equals 1 if the participant thinks her Task 2 performance is above average and 0 otherwise. For the team tournament, Guesswin equals 1 if the participant thinks the sum of her Task 2 performance and her teammate's Task 2 performance exceeds the sum of their opponents'Task 2 performances. When controlling for beliefs, it can be seen from table 3 that the coefficient of Team in men's regression is only weakly reduced showing that men's poor confidence in their chances of winning the tournament as part of a team must only explain a small part of their change in competitive behavior.

Figures 4 and 5 show that if high-performing men are more likely to enter the team tournament with a teammate of the same level than the team tournament $(p=0.02)$, they are about as likely to submit their past performance to the team tournament and the team tournament with a teammate of the same level $(p=0.76){ }^{8}$ Remember that the decision to submit a past performance to a tournament is identical to the decision to enter a tournament as far as overconfidence, risk aversion and the uncertainty about one's teammate's ability are

\footnotetext{
${ }^{8}$ The proportions of low-performing and high-performing women respectively entering and submitting a past performance to each of the three tournaments can be found in figures 11 and 12 of the appendix.
} 
Table 3: Linear Probability Model for Men's Decisions to Enter the Individual and Team Tournaments (Tasks 3, 4)

\begin{tabular}{lcc}
\hline Regressors & $(1)$ & $(2)$ \\
\hline \hline Team & -0.26 & -0.23 \\
& $(0.01)$ & $(0.02)$ \\
Prob & 0.21 & -0.16 \\
& $(0.48)$ & $(0.42)$ \\
Guesswin & & 0.48 \\
& & $(0.00)$ \\
\hline Observations & 78 & 78 \\
\hline \hline
\end{tabular}

Linear probability model using clusters for each participant and each session.

The table presents marginal effects computed at a man in the individual tournament with a $50 \%$ chance of winning the tournament. P-values are in brackets.

concerned. It only differs in the fact that it does not involve a future performance. In particular, when deciding whether to submit a past performance to the team tournament, one knows her teammate has performed the task already under an individual remuneration scheme (piece rate). High-performing men thus do not seem to mind being matched to a probably less efficient teammate as long as the task has been performed previously to this decision. Therefore, it cannot be the case that the reason behind men's behavior is their fear of being matched to a low-performing teammate or their unwillingness to help such a teammate get higher payoffs. The hypothesis that high-performing men do not want to be subjected to the free-riding behavior of their teammate must be favored.

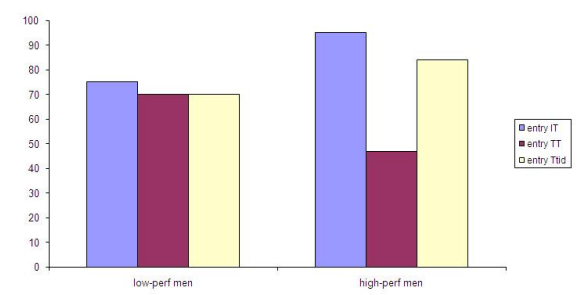

Figure 4. Proportion of low-performing and highperforming men entering each of the three tournaments.

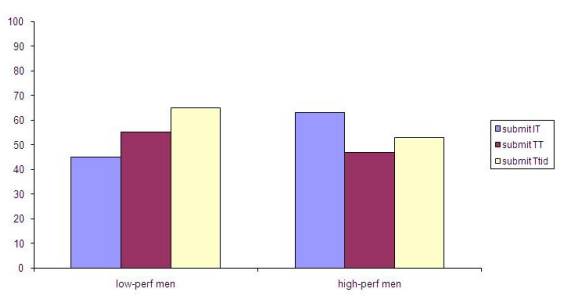

Figure 5. Proportion of low-performing and highperforming men submitting a past performance to each of the three tournaments.

In the last regression of table 4, the dummy Submit corresponding to the decision to submit the Task 1 performance to a tournament is added to the regressors. It can be seen that a participant who chooses to submit her past performance to a tournament is more likely to take the decision of entering this same tournament. However, apart from this, the introduction of Submit into the regressors does not change much the results showing that men's reluctance to enter the team tournament does not have much to do with low 
Table 4: Linear Probability Model for Men's Tournament-Entry Decision (Tasks 3, 4 and 5)

\begin{tabular}{lcccc}
\hline Regressors & $(1)$ & $(2)$ & $(3)$ & $(4)$ \\
\hline \hline Team & -0.26 & -0.19 & 0.05 & -0.01 \\
& $(0.01)$ & $(0.01)$ & $(0.90)$ & $(0.47)$ \\
Prob & 0.16 & 0.26 & 0.92 & 0.69 \\
& $(0.48)$ & $(0.18)$ & $(0.02)$ & $(0.03)$ \\
IdPartn & & 0.11 & 0.11 & 0.06 \\
& & $(0.06)$ & $(0.07)$ & $(0.12)$ \\
Prob*Team & & & -0.84 & -0.52 \\
& & & $(0.07)$ & $(0.28)$ \\
Submit & & & & 0.34 \\
& & & & $(0.00)$ \\
\hline Observations & 78 & 117 & 117 & 117 \\
\hline \hline
\end{tabular}

Linear probability model using clusters for each participant and each session.

The table presents marginal effects computed at a man in the individual tournament with a $50 \%$ chance of winning the tournament. $\mathrm{P}$-values are in brackets.

confidence in their teammate or their unwillingness to help her get higher payoff but rather with their fear of free-riding behaviors from a low-performing teammate.

\section{Consequences of the Type of Competition on Efficiency.}

The introduction of the team tournament was successful in wiping out the gender gap in tournament entry. It is obviously essential to closely study the consequences of the team tournament on other aspects in order to weigh up the pros and cons. This section studies the consequences of the type of tournament on participants' payoffs as well as on the pool of entrants and its quality, i.e. the performance of those who choose to enter. It enables one to draw some conclusions on the implications of the choice of a type of competition for both contestants and recruiters.

How the type of tournament influences the quality of the pool of entrants is an important question. Figure 6 represents the percentage of participants who chose to enter each of the three tournaments conditional on Task 2 performance level. Compared with the individual tournament, more low-performing and fewer high-performing participants choose to enter the team tournament. This obviously affects the average performance of the entrants, even though the difference in performance between the entrants of the individual and team tournament is not significant ( $p=0.18$ for the two-sided Mann Whitney test and $p=0.09$ for the onesided test). On the other hand, the proportion of entrants of each performance level in the TTid is similar to 
the proportion of entrants in the individual tournament.

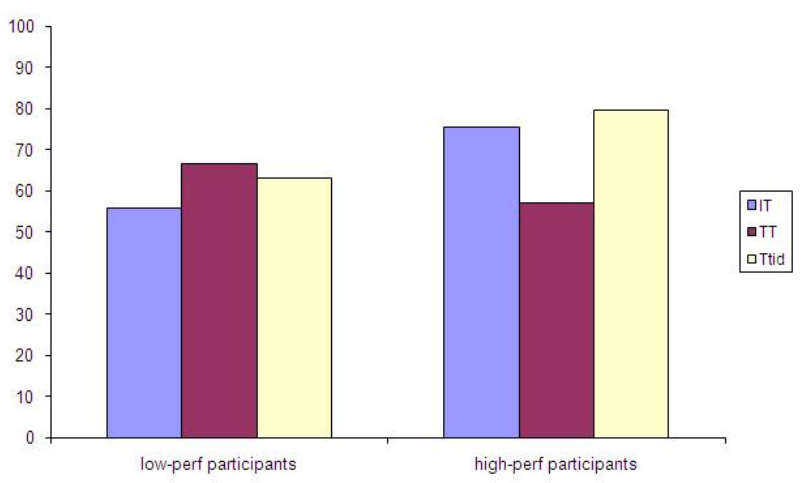

Figure 6. Proportion of entrants in the tournaments conditional on performance level.

Figure 7 shows the average performances of male and female entrants in the three kinds of tournament. Each time, men are slightly better than women but not significantly so. We can observe a decrease of men's performance when the tournament becomes team-based which is, however, not significant. It may be due to men shirking when part of a team, but it may also be caused by the crowding out effect of the team tournament on high-performing men. Female entrants' performance, on the other hand, is very stable across tournaments. In consequence, the fact that the tournament is team-based does not negatively affect women's performance. Still, the average performance of entrants is lower under the team tournament (6.48) than under the individual tournament (7.48). Men's performance goes up again when participants know that they will be matched with a teammate of the same level.

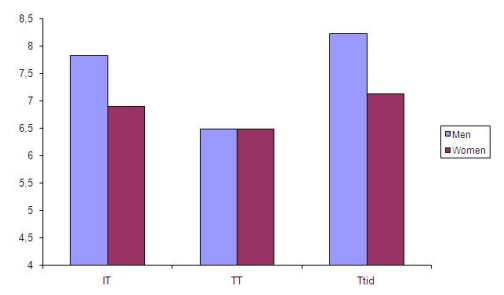

Figure 7. Performance of male and female entrants in the three tournaments.

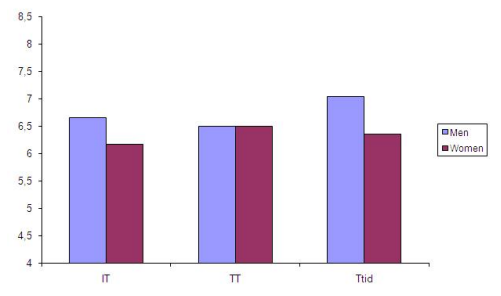

Figure 8. Performance of men and women who chose to enter the TT in the three tournaments.

In order to check whether male entrants' average performance is lower under the team tournament than under the individual tournament because of shirking behaviors, I look at differences in performance by men who chose to enter the team tournament in the three kinds of tournament. In Figure 8 it appears that men who chose to enter the team tournament do not perform significantly differently in the individual and the team tournament. I can therefore rule out shirking as an explanation for the decrease in performance of male 
entrants between the Individual and the team tournament. The remaining explanation is the crowding out effect of high-performing men when the tournament is team-based and participants do not know anything about their teammate's ability.

Team competition seems to be the solution to get a gender-balanced pool of tournament entrants. Nevertheless, the uncertainty about their teammate has a crowding out effect on high-performing men, while low-performing men are prompted to enter. Providing information about one's teammate's ability seems to be the condition to make the gender gap in tournament entry disappear without decreasing the average ability of entrants.

\section{Conclusion}

This article aims at studying the effect of a tournament being team-based rather than individual on the gender gap in tournament entry. The results allow a better understanding of the gender gap in competitiveness and provide a way of obtaining a gender-balanced pool of entrants. While a large and significant gender gap in entry in the individual tournament is found in line with NV and NSV, no gender gap is found in entry in the team tournament. Women do not choose to enter the tournament significantly more often when it is team-based but men enter significantly less as part of a team than alone. A first potential explanation for men's change in competitive behavior cound be that high-performing men do not enjoy competition as much when the victory is shared with a teammate. As high-performing men are found to be willing to enter a team competition provided they know their teammate will be of level close to their own, one can rule out this first possibility. Another explanation could be that men are reluctant to help a less able teammate get higher payoffs. However, this does not seem to be the main driving force behind men's behavior as highperforming men do not seem to mind submitting a past performance to a team competition even when they have no information on their teammate's performance level. Since the main difference between entering a team tournament and submitting a past performance to the same tournament is that in the latter both teammate's performances have already been completed, high-performing men seem to fear being subjected to the free-riding behavior of a probably less able teammate. However, they do not mind being matched to a less efficient teammate as long as her performance has been completed previously to her decision to submit it to a team competition.

This experiment provides a way of wiping out the gender gap in tournament entry as men and women are as likely to enter the team competition. However, when looking more closely at the consequences on 
welfare aspects of the tournament being team-based, it appears that it negatively affects the quality of the pool of entrants by crowding out the high-performing men from tournament entry.

There is, nevertheless, a way of getting a gender-balanced pool of entrants without driving away highperforming men from competition by providing contestants with information about their teammate's ability, namely, telling them they will be matched with a teammate of level close to their own.

In the present article, I chose not to consider the impact of one's teammate and opponents' gender on her decision to enter competitions. However, it is very likely that this has an impact. Indeed, Niederle et al. (2008) showed that a reason why affirmative action was successful in enticing women to enter competition was because women are more comfortable competing against other women. Furthermore, Ivanova-Stenzel and Kübler (2005)'s results suggest that competitive performances are affected by teammates' gender and Delfgaauw et al. (2009) show in a field experiment that sales competitions have a large effect on sales growth, but only in stores where the store's manager and a large fraction of the employees have the same gender. Future research may therefore focus on the impact of one's teammate and opponents' gender on one's willingness to enter a team competition. 


\section{References}

Altonji, J. and R. Blank (1999). Handbook of Labor Economics, Volume 3, Chapter Race and Gender in The Labor Market, pp. 3144-3259. Elsevier Science.

Anker, R. (1998). Gender and jobs: Sex segregation of occupations in the world. Technical report, International Labor Office: Geneva.

Bertrand, M. and K. Hallock (2001). The gender gap in top corporate jobs. NBER Working Papers.

Bornstein, G. and I. Yaniv (1998). Individual and group behavior in the ultimatum game : Are groups more "rational" players? Experimental Economics 1, 109-118.

Cason, T. and V.-L. Mui (1997). A laboratory study of group polarization in the team dictator game. Economic Journal 107, 1465-1483.

Charness, G. and M. Jackson (2009). The role of responsibility in strategic risk-taking. Journal of Economic Behavior and Organization 69, 241-247.

Charness, G., L. Rigotti, and A. Rustichini (2007). Individual behavior and group membership. American Economic Review 97, 1340-1352.

Chen, Y. and S. X. Li (2009, March). Group identity and social preferences. American Economic Review 99(1), 431-457.

Cooper, D. and J. Kagel (2005, June). Are two heads better than one? team versus individual play in signaling games. American Economic Review 95(3), 477-509.

Cox, J. C. and C. Hayne, Stephen (2006). Barking up the right tree: are small groups rational agents? Experimental Economics 9(3), 209-222.

De la Rica, S., J. Dolado, and V. Llorens (2008, Juillet). Ceilings or floors? gender wage gaps by education in spain. Population Economics 21(3), 751-776.

Delfgaauw, J., R. Dur, J. Sol, and W. Verbeke (2009). Tournament incentives in the field: Gender differences in the workplace. Tinbergen Institute Discussion Paper (2009-069/1). 
Eckel, C. and P. Grossman (1998). Are women less selfish than men?: Evidence from dictator experiments. The economic journal 108, 726-735.

Eckel, C. and P. Grossman (2001). Chivalry and solidarity in ultimatum games. Economic Inquiry 39(2), $171-188$.

Eckel, C. and P. Grossman (2008, September). Differences in the economic decisions of men and women: Experimental evidence, Volume Handbook of Results in Experimental Economics.

Fox, R. and J. Lawless (2004, March). Entering the arena? gender and the decision to run for office. American Journal of Political Science 48(2), 264-280.

Goldin, C. and C. Rouse (2000). Orchestrating impartiality: The impact of "blind" auditions on female musicians. American Economic Review 90, 715-741.

Greiner, B. (2004). An Online Recruitment System for Economic Experiments. (Kremer, K.,Macho, V., (Eds.), ed.).

Gupta, N., A. Poulsen, and M.-C. Villeval (2005). Male and female competitive behavior: Experimental evidence. IZA Discussion Paper No. 1833.

Healy, A. J. and J. G. Pate (2010). Can teams help to close the gender competition gap? Forthcoming in The Economic Journal.

Ivanova-Stenzel, R. and D. Kübler (2005). Courtesy and idleness: Gender differences in team work and team competition. SFB 649 Discussion Paper, Humboldt University.

Keser, C. and C. Montmarquette (2007). Voluntary teaming and effort. Working Paper $n \check{r} 745$. German Institute for Economic Research.

Kocher, M. and M. Sutter (2005, January). The decision maker matters: Individual versus group behaviour in experimental beauty-contest games. The Economic Journal 115, 200-223.

List, J. and coauthors (2010). Gender and job sorting: Evidence from a natural field experimenť̌.

Luhan, W., M. Kocher, and M. Sutter (2009). Group polarization in the team dictator game reconsidered. Experimental Economics 12, 26-41. 
Niederle, M., C. Segal, and L. Vesterlund (2008). How costly is diversity? affirmative action in competitive environments. NBER Working Paper NO. W13923.

Niederle, M. and L. Vesterlund (2007). Do women shy away from competition? do men compete too much? Quarterly Journal of Economics 122, 1067-1101.

Ortmann, A. and L. Tichy (1999). Gender differences in the laboratory: evidence from prisoner's dilemma games. Journal of economic behavior and organization 39, 327-339.

Rockenbach, B., A. Sadrieh, and B. Mathauschek (2007). Teams take the better risks. Journal of Economic Behavior and Organization 63, 412-422.

Shupp, R. and A. Williams (2007). Risk preference differentials of small groups and individual. The Economic Journal 118(525), 258-283.

Sutter, M. (2009). Individual behavior and group membership: Comment. Forthcoming in American Economic Review.

Tajfel, H. (1970). Experiments in intergroup discrimination. Scientific American 223, 96-102.

Zeiliger, R. (2000). A presentation of regate, internet based software for experimental economics. http://www.gate.cnrs.fr/ zeiliger/regate/RegateIntro.ppt, GATE. 


\section{Appendices}

\section{A Consequences of the Type of Tournament on the Probability of Winning and Expected Payoffs}

The consequences of the tournament being team-based on the quality of the pool of entrants and their payoffs will partly depend on the change in the probability of winning and expected payoffs. Remember that, when entering the team tournament, a participant knows that she will be matched with a teammate who also chose to enter the team tournament. Hence, the level of other participants who chose to enter has an impact on a participant's probability of winning if she enters, as well as on her payoffs if she enters and wins (as each teammate of the winning team earns 1 euro times the average performance of the team). First of all, let us look at Figures 9 and 10 which represent respectively the probability of winning ${ }^{9}$ and the expected payoffs

10 for each of the three tournaments conditional on performance.

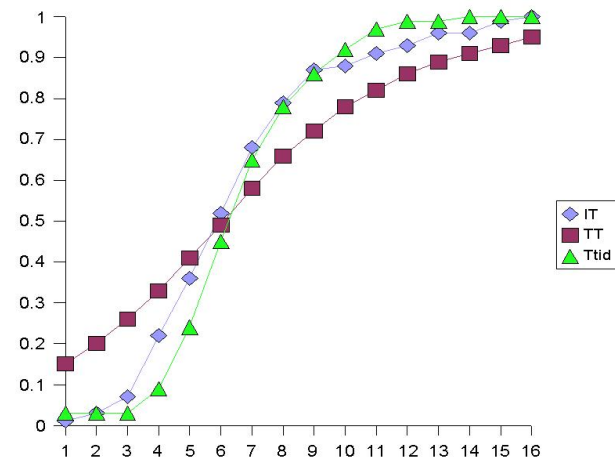

Figure 9. Probability of winning the tournaments conditional on performance.

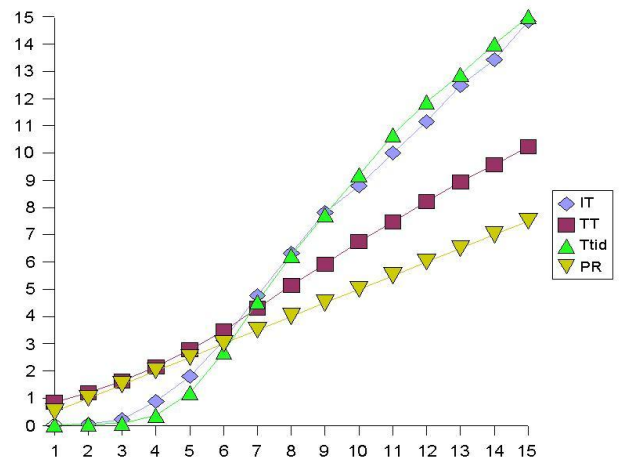

Figure 10. Expected payoffs of the tournaments conditional on performance.

\footnotetext{
${ }^{9} 1.000 .000$ pairs of opponents' performances were drawn by sampling with replacement from the Task 2 performances of the 76 participants. 1.000 .000 teammate's performances were drawn from the Task 2 performances of the potential teammates i.e. of the participants who chose to enter the team tournament. For each level of performance, the probability of winning the individual tournament was computed by calculating the number of times out of 1.000 .000 this given performance exceeded the first opponent's performance. Similarly, for each level of performance, the probability of winning the team tournament was computed by calculating the number of times out of 1.000 .000 this given performance plus the partner's performance exceeded the sum of both opponent's performances. Finally, the probability of winning the team tournament with a teammate of the same level was found by computing how many times the double of a given performance exceeded the sum of the two opponents' performances.

${ }^{10} 1.000 .000$ pairs of opponents' performances and 1.000 .000 teammate's performances were drawn by sampling with replacement from the Task 2 performances of the 76 participants. For each level of performance, the expected payoff from entering the individual tournament was computed in the following way. For each given performance, the payoff corresponding to each of the 1.000 .000 first opponent's performances was computed and averaged. Similarly, for each level of performance, the expected payoff from entering the team tournament was computed by calculating the payoff corresponding to each of the 1.000 .000 different sets of one teammate's and two opponents' performances and averaging it.
} 
It can be seen that while for the individual and the team tournament with a teammate of the same level the probabilities of winning and the expected payoffs are both close, such is not the case for the team tournament. Indeed, the team tournament provides higher expected payoffs than the two other tournaments for low-performing participants and lower expected payoffs for high-performing participants.

The average Task 2 performance of the team tournament entrants (6.52) is lower than the average Task 2 performance of the whole group (6.86) but it is far from being significant. Nevertheless this is not unexpected, as the difference of performance between those who did choose to enter and those who did not is not significant (a two-sided Mann Whitney test yields $p=0.30$ ) implying all the more that the difference of performance between the entrants and the whole group is not significant either.

\section{B Women's competitive behavior}

It can be seen from figures 11 and 12 that women exhibit competitive behaviors very different from men's.

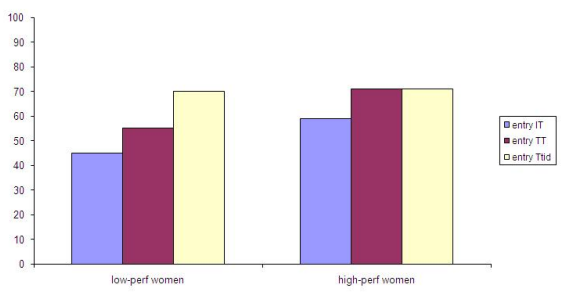

Figure 11. Proportion of low-performing and highperforming women entering each of the three tournaments.

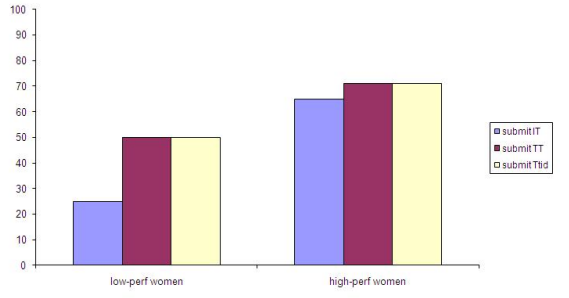

Figure 12. Proportion of low-performing and highperforming women submitting a past performance to each of the three tournaments.

Firstly, high-performing women enter in very similar proportions in each of the three tournaments. It is not the case that high-performing women shy away from team competition and neither do they feel more comfortable entering a team competition when they know their teammate will be of level close to their own. Secondly, women's decision to submit a past performance to a given tournament is not very different from their decision to enter the same tournament. This is especially true of high-performing men.

\section{Instructions}

The experiment is composed of 8 tasks. Before each task, you will be carefully explained what the task is about and have the opportunity to ask as many questions as you need. Please remember that you are not 
allowed to communicate in any way with one another. At the end of the experiment two of the eight tasks you will have completed will be randomly chosen to determine your payoffs.

Task 1. Piece Rate: In task 1, you will have 3 minutes to solve as many additions of 5 two-digits numbers as you can. You are allowed to use the scratch paper you have been given. If Task 1 is one of the two tasks randomly chosen for payment, you will receive 50 cents per addition correctly solved. At the end of Task 1 , a screen will indicate you how many additions you solved correctly.

\section{NEXT PAGE}

Task 2. Individual Tournament: You will have 3 minutes to solve as many additions of 5 two-digits numbers as you can. If Task 2 is chosen for payment, you will receive 1 euro per correct answer if you solved more additions than a randomly chosen opponent present in the room, otherwise you will receive nothing. You will earn 50 cents per addition correctly solved in case of a tie.

At the end of Task 2, a screen will indicate how many additions you solved correctly but you will know whether you won your tournament only at the end of the experiment.

\section{NEXT PAGE}

Task 3. Choice between Piece Rate and Individual Tournament: Before performing your 3 minutes of additions, you will have to choose whether you want to be paid according to the Piece Rate (50 cents per correct answer) or the Individual Tournament compensation scheme.

If you choose the Piece Rate, you will receive 50 cents per addition correctly solved during Task 3.

If you select the tournament, you will receive 1 euro per correct answer if your Task 3 performance exceeds the Task 2 performance of a randomly chosen opponent, otherwise you will receive nothing. You will earn 50 cents per addition correctly solved during Task 3 in case of a tie.

At the end of Task 3, a screen will indicate how many additions you solved correctly but you will know whether you won your tournament, if you choose to engage in it, only at the end of the experiment.

\section{NEXT PAGE}

\section{Task $4^{11}$. Choice between submitting Task 1 performance to Piece Rate or Individual Tournament: No} additions to do here, the performance which will determine your payoffs is your Task 1 performance. If you choose to submit your Task 1 performance to the Piece Rate, you will receive 50 cents times your Task 1 performance.

\footnotetext{
${ }^{11}$ The task which was presented as Task 4 to the participants is labeled "Task 3 prime" in the core of the article
} 
If you choose to submit your Task 1 performance to the individual tournament, you will receive 1 euro per addition correctly solved in Task 1 if you solved more additions in Task 1 than your randomly chosen opponent, otherwise you will receive nothing. You will earn 50 cents per addition correctly solved during Task 1 in case of a tie.

You will know whether you won your tournament, if you choose to submit your Task 1 performance to the tournament, only at the end of the experiment.

\section{NEXT PAGE}

Task $5^{12}$. Choice between Piece Rate and Team Tournament: You have to choose whether they want to be paid according to the Piece Rate or the Team Tournament. The Team Tournament is a two to two competition.

If you choose the Piece Rate, you will receive 50 cents per addition correctly solved during Task 4.

If you choose the Team Tournament, two opponents will be randomly drawn among the other participants present in the room. One teammate will be randomly drawn among the participants who chose the team tournament. If the number of additions solved by your team during Task 4 exceeds the number of additions solved by the opposing team during Task 2, each teammate of your team will receive 1 euro times the average score of the team. Otherwise, you will receive nothing. You and your teammate will each earn 50 cents times the average score of the team during Task 4 in case of a tie.

At the end of Task 4, a screen will indicate how many additions you solved correctly but you will know whether you won your tournament, if you choose to engage in it, only at the end of the experiment. You will not know either your teammate's performance until the end of the experiment.

\section{NEXT PAGE}

\section{Task $6^{13}$. Choice between submitting Task 1 performance to Piece Rate or Team Tournament: No} additions to do here, the performance which will determine your payoff is your Task 1 performance. If you choose to submit your Task 1 performance to the Piece Rate, you will receive 50 cents times your Task 1 performance.

If you choose to submit your Task 1 performance to the Team Tournament, two opponents are randomly drawn among the other participants present in the room. One teammate is randomly drawn among the participants who chose to submit to the Team Tournament. If the number of additions solved by your team

\footnotetext{
${ }^{12}$ The task which was presented as Task 5 to the participants is labeled "Task 4 " in the core of the article

${ }^{13}$ The task which was presented as Task 6 to the participants is labeled "Task 4 prime" in the core of the article
} 
during Task 1 exceeds the number of additions solved by the opposing team during Task 1, you and your teammate will each receive 1 euro times the average score of the team. Otherwise, you will receive nothing. You and your teammate will each earn 50 cents times the average score of the team during Task 1 in case of a tie.

\section{NEXT PAGE}

\section{Task $7^{14}$. Choice between Piece Rate and Team Tournament with a teammate of the same level (TTid} henceforth):

If you choose the Piece Rate, you will receive 50 cents per addition correctly solved during task 5.

If you choose the Team Tournament with a teammate of the same level, two opponents will be randomly drawn among the other participants present in the room. Your teammate will be the participant, who chose the team tournament with a teammate of the same level, whose Task 2 performance was the closest to your own Task 2 performance. If the number of additions solved by your team during Task 5 exceeds the number of additions solved by the opposing team during Task 2, you and your teammate will each receive 1 euro times the average Task 5 score of your team. Otherwise, you and your teammate will receive nothing. You and your teammate will each earn 50 cents times the average score of the team during Task 5 in case of a tie. At the end of Task 5, a screen will indicate how many additions you solved correctly but you will know whether you won your tournament, if you choose to engage in it, only at the end of the experiment. You will not know either your teammate's performance until the end of the experiment.

\section{NEXT PAGE}

\section{Task $8^{15}$. Choice between submitting Task 1 performance to Piece Rate or Team Tournament with a}

teammate of the same level: No additions to do here, the performance which will determine your payoff is your Task 1 performance.

If you choose to submit your task 1 performance to the Piece Rate, you will receive 50 cents times your Task 1 performance.

If you choose to submit your task 1 performance to the team tournament with a teammate of the same level, two opponents will be randomly drawn from among the other participants present in the room. Your teammate will be the participant, who chose to submit to the team tournament with a teammate of the same level, whose Task 2 performance was the closest to your own Task 2 performance. If the number of additions

\footnotetext{
${ }^{14}$ The task which was presented as Task 7 to the participants is labeled "Task 5 " in the core of the article

${ }^{15}$ The task which was presented as Task 8 to the participants is labeled "Task 5 prime" in the core of the article
} 
solved by your team during Task 1 exceeds the number of additions solved by the opposing team during Task 1 , you and your teammate will each receive 1 euro times the average score of their team. Otherwise, you and your teammate will receive nothing. You and your teammate will each earn 50 cents times the average score of the team during Task 1 in case of a tie.

\section{NEXT PAGE}

Belief-assessment Questions The experiment is now almost over. You just have to answer a few questions about the experiment. For each correct guess, you will earn 1 additional euro.

At Task 4, whether you chose to enter the team tournament or not, two opponents were randomly drawn among the other participants present in the room. One teammate was randomly drawn among the participants who chose the Team Tournament. Knowing that your own Task 2 performance will be recalled to you on the next screen, please guess the task 2 performances of your 2 opponents and your teammate. Also guess the Task 2 performance of the average participant present in the room.

At Task 4 prime, whether you chose to enter the team tournament or not, two opponents were randomly drawn among the other participants present in the room. One teammate was randomly drawn among the participants who chose the to submit their Task 1 performance to the Team Tournament. Knowing that your own Task 1 performance will be recalled to you on the next screen, please guess the Task 1 performances of your 2 opponents and your teammate. Also guess the Task 1 performance of the average participant present in the room. 
DISCUSSION PAPERS 2011

Marie-Pierre Men too sometimes shy away from competition:

SP II $2011-201$

Dargnies

The case of team competition

Marie-Pierre Social Identity and Competitiveness

SP II $2011-202$ 
Bei Ihren Bestellungen von WZB-Papers schicken Sie bitte unbedingt einen an Sie adressierten Aufkleber mit sowie je paper eine Briefmarke im Wert von 0,51 Euro oder einen "Coupon Reponse International " (für Besteller aus dem Ausland)
Please send a self addressed label and postage stamps in the amount of 0.51 Euro or a "CouponReponse International" (if you are ordering from outside Germany) for each WZB-paper requested

\section{Absender / Return Address:}

Wissenschaftszentrum Berlin

für Sozialforschung

Presse- und Informationsreferat

Reichpietschufer 50

D-10785 Berlin-Tiergarten

Hiermit bestelle ich folgende(s) Discussion paper(s):

Bestell-Nr. / Order no.
Please send me the following Discussion paper(s):

Autor/in, Kurztitel /Author(s) / Title(s) in brief 